\title{
Pretreatment Out-of-Pocket Expenses for Presumptive Multidrug-Resistant Tuberculosis Patients, India, 2016-2017
}

Priya Rathi, Kalpita Shringarpure, Bhaskaran Unnikrishnan, Vineet Kumar Chadha, Vishak Acharya, Abirami Nair, Karuna D. Sagili, Suresh Shastri

In India, under the National Tuberculosis Elimination Programme, the government provides free treatment for multidrug-resistant tuberculosis; however, many patients seek care elsewhere, which is costly. To determine those out-ofpocket expenses, we interviewed 40 presumptive patients and found that they spent more than their median annual income before registering for the government program.

I

n India, the annual economic loss resulting from tuberculosis (TB) is US $\$ 3$ billion (1). Those in the economically productive age group (15-54 years) account for $>70 \%$ of the total burden (1). Incidence of multidrug-resistant TB (MDR TB) is higher in India than anywhere else in the world; $\approx 99,000$ new cases of MDR TB occur in India each year (1). Treatment of MDR TB is more complex, challenging, and costly to manage than that of drug-sensitive TB (2-4). In India, MDR TB is treated free of cost through programmatic management of drug-resistant TB (PMDT) under the National Tuberculosis Elimination Programme (5). However, most patients seek healthcare from the private sector and some resort to alternative forms of medicine, often preferring self-medication and consulting quacks over visiting the PMDT center $(6,7)$. This behavior not only results in delayed

Author affiliations: Kasturba Medical College, Mangalore, Manipal Academy of Higher Education, Manipal, India (P. Rathi,

B. Unnikrishnan, V. Acharya, A. Nair); Medical College Baroda, Baroda, India (K. Shringarpure); Central Leprosy Teaching and Research Institute, Tamil Nadu, India (V.K. Chadha); National Tuberculosis Institute, Epidemiology and Research, Division Bengaluru, India (V.K. Chadha); International Union against Tuberculosis and Lung Disease, South East Asia Office, New Delhi, India (K.D. Sagili); Lady Willington State TB Centre, Bengaluru (S. Shastri)

DOI: https://doi.org/10.3201/eid2605.181992 diagnosis but also increases prediagnostic expenses (7). Increased expenses accompanied with loss of wages can compel patients and their families affected by TB to borrow money, take loans, or even sell their assets, thereby accentuating any existing financial crises in the family (6-9). Hence, we estimated the direct and indirect out-of-pocket expenses incurred for diagnosis and pretreatment evaluation by presumptive MDR TB patients in Mangalore, India.

\section{The Study}

Mangalore is a coastal city in the state of Karnataka, India. The state has 6 PMDT centers. Presumptive MDR TB patients, when referred to PMDT centers, are subjected to drug sensitivity testing, preferably by use of a rapid molecular test (cartridge-based nucleic acid amplification assay), line probe assay, or culture, per PMDT guidelines (10). Those with an MDR TB diagnosis are admitted to the center for a week for pretreatment evaluation. All services provided under PMDT are free of cost to the patient (10).

We included in our study all adults $(\geq 15$ years of age) with MDR TB who were registered under PMDT during August 2016-April 2017. By using a valid, pretested, semistructured tool, we interviewed patients about various costs incurred by themselves, their families, or both, from the time they became a presumptive MDR TB patient until they underwent pretreatment evaluation at PMDT. Information about various costs reported by patients was validated with bills, if available. We used the following cost categories: direct medical, direct nonmedical, indirect, and coping. Direct medical costs are expenses incurred during diagnosis and treatment of illness; direct nonmedical costs are costs of food, accommodations, and additional nutrition/supplements; indirect costs are the loss of wages because of illness; 


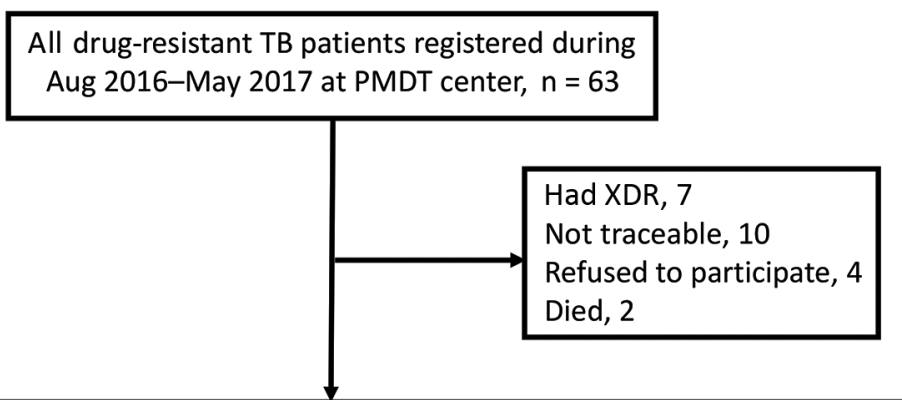

Patients enrolled, $\mathrm{n}=40$

In-person interview (admitted for pretreatment evaluation), $\mathrm{n}=16$

Telephonic interview (undergoing home-based care after pretreatment evaluation), $n=24$
Figure 1. Flow chart showing patient enrollment in study of pretreatment out-of-pocket expenses for presumptive multidrug-resistant tuberculosis patients, India, 2016-2017. and coping costs are the costs of coping mechanisms (assets sold, school dropouts, loans, and money borrowed) (Appendix, https://wwwnc.cdc.gov/EID/ article/26/5/18-1992-App1.pdf). Of the 40 MDR TB patients, the 16 who were admitted during the study period were interviewed in person and the 24 who continued home-based treatment were interviewed

\begin{tabular}{|c|c|}
\hline Characteristic & No. (\%) \\
\hline \multicolumn{2}{|l|}{ Sex } \\
\hline M & $28(70)$ \\
\hline $\mathrm{F}$ & $12(30)$ \\
\hline \multicolumn{2}{|l|}{ Education } \\
\hline Illiterate & $5(12.5)$ \\
\hline Primary school & $15(37.5)$ \\
\hline Secondary school & $14(35.0)$ \\
\hline Graduation/professional course & $6(15.0)$ \\
\hline \multicolumn{2}{|l|}{ Type of occupation } \\
\hline Salaried job & $13(32.5)$ \\
\hline Daily wage & $9(22.5)$ \\
\hline Business owner & $5(12.5)$ \\
\hline Homemaker & $8(20.0)$ \\
\hline Other† & $5(12.5)$ \\
\hline \multicolumn{2}{|l|}{ Place of residence } \\
\hline Urban & $12(30.0)$ \\
\hline Rural & $28(70.0)$ \\
\hline \multicolumn{2}{|l|}{ Socioeconomic status $\dagger$} \\
\hline Upper class & $6(15.0)$ \\
\hline Upper-middle class & $14(35.0)$ \\
\hline Middle class & $8(20.0)$ \\
\hline Lower-middle class & 7 (17.5) \\
\hline Lower-class & $5(12.5)$ \\
\hline \multicolumn{2}{|c|}{ Health facility sequence where MDR TB diagnosis made } \\
\hline First & $23(57.5)$ \\
\hline Second & $14(35.0)$ \\
\hline Third & $3(7.5)$ \\
\hline Fourth & 0 \\
\hline \multicolumn{2}{|c|}{ Type of healthcare facility visited by patients before PMDT } \\
\hline Private & $24(60)$ \\
\hline Public & $16(40)$ \\
\hline \multicolumn{2}{|c|}{$\begin{array}{l}\text { *MDR TB, multidrug-resistant TB; PMDT, programmatic management of } \\
\text { drug-resistant TB; TB, tuberculosis. } \\
\text { †Modified BG Prasad Classification } \\
\text { (https://www.ijcmph.com/index.php/ijcmph/article/view/1242/1005). }\end{array}$} \\
\hline
\end{tabular}

by telephone (Figure 1). Ethics approval was obtained from the Institutional Ethics Committee of Kasturba Medical College, Mangalore, and the Ethics Advisory Group of The International Union against Tuberculosis and Lung Disease, Paris, France.

Data were double entered in EpiData version 3.1 software (https:/ / www.epidata.dk) and analyzed by using SPSS Statistics 25.0 (https://www.ibm.com) and EpiData analysis 2.2.2.183 software. Direct and indirect costs were summarized as median and interquartile ranges (IQRs). Categorical variables were expressed in proportions. Costs were collected by using Indian rupees (INR) converted to United States dollars (USD) based on the 2016 conversion rate (1 USD $=66.3731$ INR). To compare the costs across different countries, we first converted the reported costs (USD) from other studies to local currency for the reported year, then adjusted them for inflation year by year until 2016 (11). Then we converted the costs back to USD by using the 2016 conversion rate (Appendix).

We included 40 of the 63 registered patients in the study. Median (IQR) age of participants was 39 (2950 ) years. Most patients were male $(28,70 \%)$, and most lived in rural areas (28,70\%). Median (IQR) reported patient family income was $\$ 608$ (\$228-\$912)/year. Of the 40 patients, 39 (97\%) had pulmonary MDR TB and $24(60 \%)$ had approached the private healthcare sector for their first clinical encounter (Table 1; Figure 2).

The median (IQR) pretreatment out-of-pocket expenses incurred by patients were $\$ 171$ (\$72-\$432) total, \$105 (\$49-\$306) direct, and \$51 (\$2-\$306) indirect. Within direct costs, direct nonmedical costs $(\$ 51)$ were more than direct medical costs (\$37). Of the direct nonmedical costs, most was spent on food (\$35). Most of the direct medical costs were for diagnostic investigation (\$18) and treatment (\$15) (Table 2).

The median total pretreatment out-of-pocket expense incurred by patients in our study is similar to 


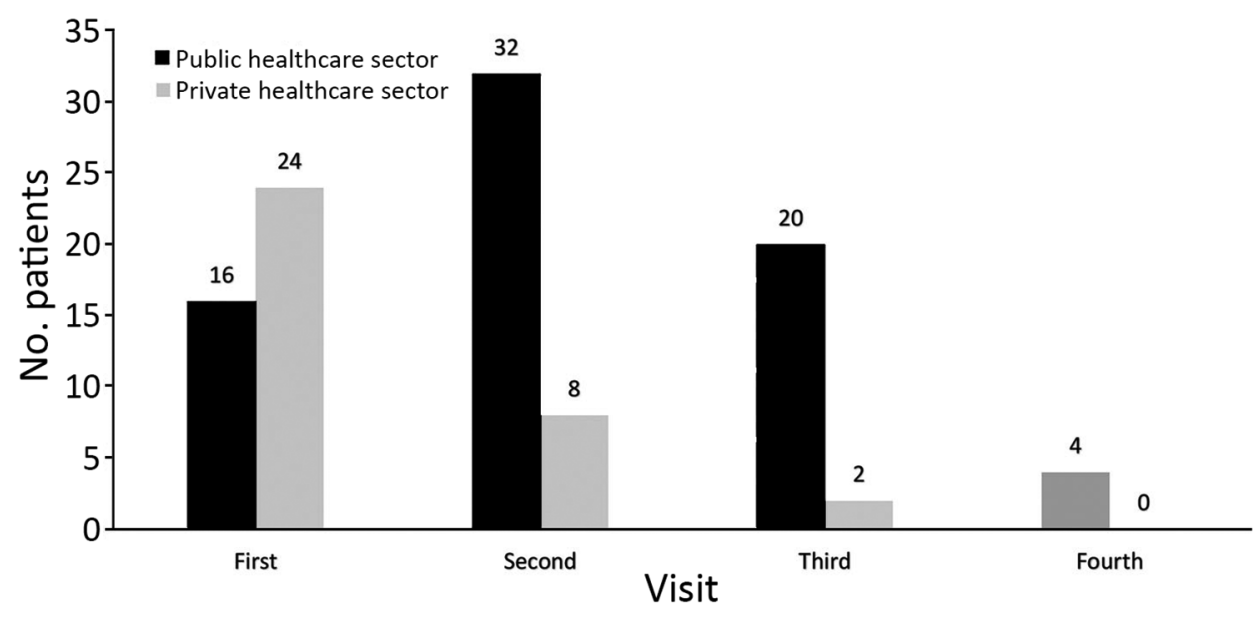

Figure 2. Distribution of visits to healthcare facilities in the public and private sectors by 40 presumptive multidrugresistant tuberculosis patients before seeking care through programmatic management of drug-resistant tuberculosis, India, 2016-2017.

that found in a study in Peru (\$210) after adjusting for inflation rate and cost conversion (12). The median direct out-of-pocket expenses are higher than the adjusted cost values found in previous comparable studies conducted in Ethiopia (\$87), Indonesia (\$47), and Peru (\$67) and lower than that reported from Cambodia (\$144) (12-15).

The median indirect out-of-pocket expense incurred by patients in India was $\$ 51$ (\$2-\$306). This finding contrasts with those of studies in Ethiopia and Indonesia, where indirect pretreatment costs after adjustment for annual inflation were substantially lower (Ethiopia \$9, Indonesia \$8) (15).

In contrast, for patients in Ecuador, the adjusted direct out-of-pocket expenses were 5 times greater than those for patients in India (\$105 vs. \$549). The adjusted indirect expenses were 10 times greater ( $\$ 51$ vs. \$578) (12) (Appendix Table).

In addition, $18(45 \%)$ patients in the study lost their job because of the disease and had to borrow money for disease management and daily household needs before receiving accurate diagnosis and appropriate treatment. The percentages of persons with job losses were substantially lower than those reported for Peru $(90 \%)$ and Ethiopia (72\%) but similar to those for Indonesia $(53 \%)(12,15)$.

Median coping cost incurred by patients in the study was $\$ 640$ (\$324-\$1,360). Wingfield et al. reported a median debt of $\$ 435$ and a loss of income of $\$ 2,450$ before diagnosis for patients in Peru (12). In the study cohort, total median cost was $\$ 171$ (\$72$\$ 432$ ), which amounted to $28 \%$ of median total family income (\$608). This expense, when combined with a coping cost of $\$ 640$, resulted in a financial burden that was 1.25 times greater than the median total family income of the cohort (\$608). Also, the cost of disease was $\$ 811$ (sum of total median cost and median coping cost), and coping costs accounted for $79 \%$ of the total. Coping cost in a study conducted in Ecuador was as high as 7 times the average annual income (14).

In our study, no patients reported school dropouts or separation in families. None of the patients reported selling assets such as property, gold, and other valuables. A total of $27(67.5 \%)$ of the patients, approximately two thirds, had already incurred catastrophic expenses before they were registered for MDR TB treatment.

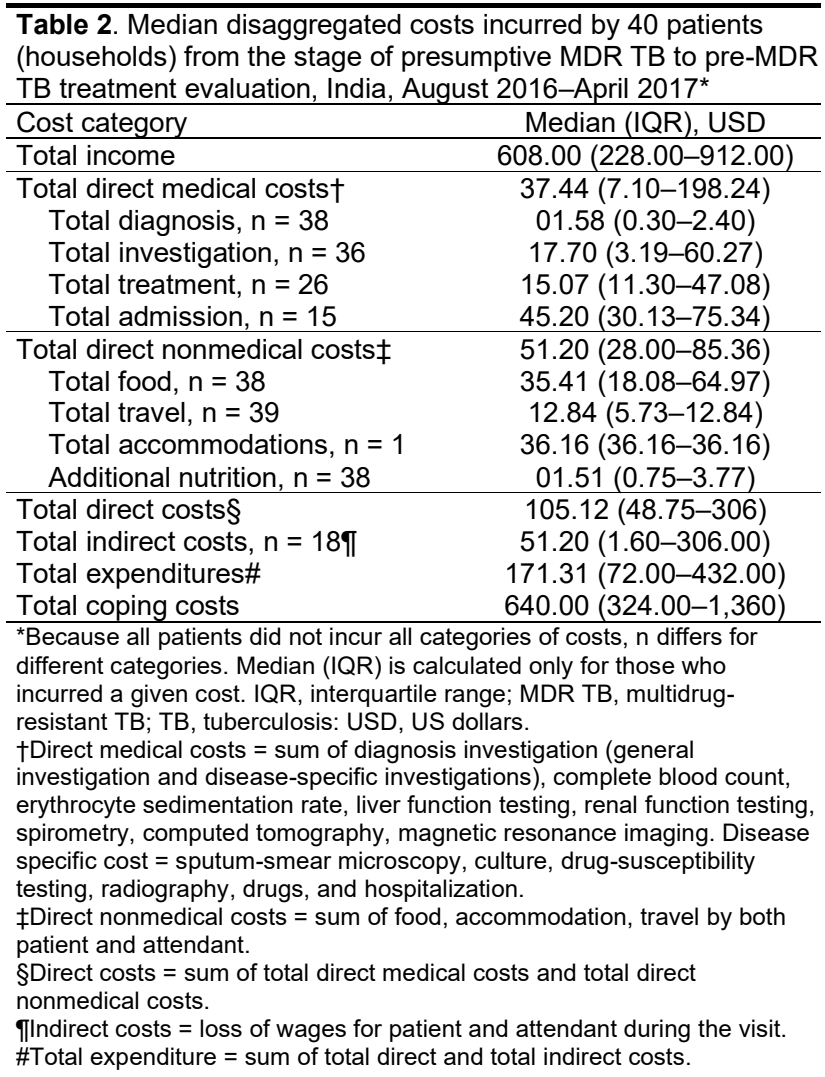




\section{Conclusions}

Our study appraised the costs expended by MDR TB patients from a single PMDT center. Determination of a complete estimate of costs borne by all MDR TB patients in India would require a comprehensive study conducted at the community level and inclusion of patients receiving treatment from the public and private healthcare sectors.

New strategies that systematically engage private providers are needed to reduce the cost burden surrounding diagnosis for vulnerable patients. The government of India may consider widening the spectrum of free services before patient enrollment in a government-monitored treatment program channeled through the private sector.

\section{Acknowledgments}

We acknowledge John E. Oeltmann and Patrick $\mathrm{K}$. Moonan for their valuable input and contributions to the study.

The study was conducted as a part of the TB Operations Research Training Project aimed at building operational research capacity within the India government National Tuberculosis Elimination Programme. This training project was conceived and implemented jointly by Central TB Division (Directorate General of Health Services, Ministry of Health and Family Welfare, Government of India), the National TB Institute (Directorate General of Health Services, Ministry of Health and Family Welfare, Government of India, Bangalore, India), the International Union Against Tuberculosis and Lung Diseases (The Union, South-East Asia Regional Office, New Delhi, India), and the US Centers for Disease Control and Prevention (Atlanta, Georgia, USA).

\section{About the Author}

Dr. Rathi is an associate professor in the Department of Community Medicine, Kasturba Medical College, Mangalore, Manipal Academy of Higher Education, Manipal. Her primary research interests are infectious and noninfectious diseases, in particular TB, HIV, and cancer.

\section{References}

1. World Health Organization. The burden of tuberculosis: economic burden. 2008 [cited 2016 Dec 20]. http:/ / www.who. int/trade/distance_learning/gpgh/gpgh3/en/index7.html

2. Udwadia ZF, Moharil G. Multidrug-resistant-tuberculosis treatment in the Indian private sector: results from a tertiary referral private hospital in Mumbai. Lung India. 2014;31:33641. https:// doi.org/10.4103/0970-2113.142101
3. Marks SM, Hirsch-Moverman Y, Salcedo K, Graviss EA, Oh P, Seaworth B, et al.; TB Epidemiologic Studies Consortium. Characteristics and costs of multidrug-resistant tuberculosis in-patient care in the United States, 2005-2007. Int J Tuberc Lung Dis. 2016;20:435-41. https:// doi.org/10.5588/ijtld.15.0575

4. World Health Organization. Guidelines for the programmatic management of drug-resistant tuberculosis, 2011 update. Geneva: The Organization; 2011.

5. Ministry of Health and Family Welfare. Revised National Tuberculosis Control Program. National Guideline for Partnership, 2014. New Delhi (India): Central TB Division, Directorate General of Health Services; 2014. p. 99.

6. Samal J. Health seeking behaviour among tuberculosis patients in India: a systematic review. J Clin Diagn Res. 2016;10:LE01-06. https:// doi.org/10.7860/JCDR/2016/ 19678.8598

7. Veesa KS, John KR, Moonan PK, Kaliappan SP, Manjunath K, Sagili KD, et al. Diagnostic pathways and direct medical costs incurred by new adult pulmonary tuberculosis patients prior to anti-tuberculosis treatment-Tamil Nadu, India. PLoS One. 2018;13:e0191591. https:// doi.org/10.1371/ journal.pone.0191591

8. Onazi O, Gidado M, Onazi M, Daniel O, Kuye J, Obasanya O, et al. Estimating the cost of TB and its social impact on TB patients and their households. Public Health Action. 2015;5:127-31. https://doi.org/10.5588/pha.15.0002

9. Udwadia ZF, Pinto LM, Uplekar MW. Tuberculosis management by private practitioners in Mumbai, India: has anything changed in two decades? PLoS One. 2010;5:e12023. https://doi.org/10.1371/journal.pone.0012023

10. Ministry of Health and Family Welfare. National Tuberculosis Elimination Program. Guidelines on programmatic management of drug-resistant TB (PMDT) in India. New Delhi (India): The Ministry; 2016.

11. Kumaranayake L. The real and the nominal? Making inflationary adjustments to cost and other economic data. Health Policy Plan. 2000;15:230-4. https://doi.org/10.1093/ heapol/15.2.230

12. Wingfield T, Boccia D, Tovar M, Gavino A, Zevallos K, Montoya R, et al. Defining catastrophic costs and comparing their importance for adverse tuberculosis outcome with multi-drug resistance: a prospective cohort study, Peru. PLoS Med. 2014;11:e1001675. https://doi.org/10.1371/journal.pmed.1001675

13. Pichenda K, Nakamura K, Morita A, Kizuki M, Seino K, Takano T. Non-hospital DOT and early diagnosis of tuberculosis reduce costs while achieving treatment success. Int J Tuberc Lung Dis. 2012;16:828-34. https:/ / doi.org/ 10.5588/ijtld.11.0688

14. Rouzier VA, Oxlade O, Verduga R, Gresely L, Menzies D. Patient and family costs associated with tuberculosis, including multidrug-resistant tuberculosis, in Ecuador. Int J Tuberc Lung Dis. 2010;14:1316-22.

15. van den Hof S, Collins D, Hafidz F, Beyene D, Tursynbayeva A, Tiemersma E. The socioeconomic impact of multidrug resistant tuberculosis on patients: results from Ethiopia, Indonesia and Kazakhstan. BMC Infect Dis. 2016;16:470-7. https:/ / doi.org/10.1186/s12879-016-1802-x

Address for correspondence: Priya Rathi, Department of Community Medicine, Kasturba Medical College, Mangalore, Karnataka 575001, India; email: priya.rathi@manipal.edu 